\title{
Individual consumers and climate change: searching for a new moral compass
}

\author{
Tanya O'Garra
}

May 2012

Centre for Climate Change Economics and Policy Working Paper No. 93

Grantham Research Institute on Climate Change and the Environment Working Paper No. 81 
The Centre for Climate Change Economics and Policy (CCCEP) was established by the University of Leeds and the London School of Economics and Political Science in 2008 to advance public and private action on climate change through innovative, rigorous research. The Centre is funded by the UK Economic and Social Research Council and has five inter-linked research programmes:

1. Developing climate science and economics

2. Climate change governance for a new global deal

3. Adaptation to climate change and human development

4. Governments, markets and climate change mitigation

5. The Munich Re Programme - Evaluating the economics of climate risks and opportunities in the insurance sector

More information about the Centre for Climate Change Economics and Policy can be found at: http://www.cccep.ac.uk.

The Grantham Research Institute on Climate Change and the Environment was established by the London School of Economics and Political Science in 2008 to bring together international expertise on economics, finance, geography, the environment, international development and political economy to create a world-leading centre for policy-relevant research and training in climate change and the environment. The Institute is funded by the Grantham Foundation for the Protection of the Environment, and has five research programmes:

1. Global response strategies

2. Green growth

3. Practical aspects of climate policy

4. Adaptation and development

5. Resource security

More information about the Grantham Research Institute on Climate Change and the Environment can be found at: http://www.Ise.ac.uk/grantham.

This working paper is intended to stimulate discussion within the research community and among users of research, and its content may have been submitted for publication in academic journals. It has been reviewed by at least one internal referee before publication. The views expressed in this paper represent those of the author(s) and do not necessarily represent those of the host institutions or funders. 


\title{
Individual consumers and climate change: searching for a new moral compass ${ }^{1}$
}

Tanya O'Garra

GIROAZ, Departamento de Fundamentos del Análisis Económico I, University of the Basque Country, Spain

Grantham Research Institute on Climate Change and the Environment, London School of Economics, UK

\begin{abstract}
Individuals and households are responsible for about one third of all carbon emissions in the UK and the US, and yet, there has been limited policy attention to this sector. This chapter proposes that voluntary engagement by individuals and households in carbon-reducing behaviours might be significantly enhanced if climate change is framed clearly, and unequivocally, as a moral issue. However, climate change has a number of features that make it difficult to apprehend as a typical moral problem. This chapter examines each of these features, and discusses how they might be re-cast so that the climate change problem takes the form of a standard moral problem. This chapter also serves as a rudimentary review of the ethics literature relevant to climate change.
\end{abstract}

\section{INTRODUCTION}

“..climate change appears to be a perfect moral storm because it involves the convergence of a number of factors that threaten our ability to act ethically" (Gardiner, 2006; p398).

There is an almost worldwide consensus that human activities associated with the burning of fossil fuels are contributing significantly to changing the world's climate.

\footnotetext{
${ }^{1}$ This paper will appear as a chapter in the forthcoming Handbook of Energy and Climate Change, edited by RogerFouquet, to be published by Edward Elgar.
} 
The IPCC (2007) report outlines the predicted and actual impacts from this changing climate, which include increasing severity of floods, melting permafrost and increased heat-related human mortality rates. Mitigation of these impacts will require serious reductions in our greenhouse gas emissions, of which carbon dioxide is the most important source.

So far, climate change mitigation policies worldwide have tended to focus on reductions from industrial and commercial sources, largely ignoring emissions from individuals and households. However, this sector is responsible for a very large proportion of total carbon emissions, with personal transport and domestic heating responsible for $30-40 \%$ of all carbon emissions in the U.S. (Vandenbergh et al, 2008), and about 32\% of carbon emissions in the UK (DECC, 2011; DfT, 2010).

Despite the significant impact of individual and residential energy-use on the climate, there has been limited policy attention to this sector. Most attempts to reduce emissions at this level have relied on voluntary approaches and, as noted by Lorenzoni et al. (2007) and Whitmarsh (2009), such approaches have had little impact on behaviour. However, any discussion of government regulation of individual behaviour to curtail emissions is a political non-starter, especially in the U.S. Thus, voluntary targets are likely to remain on the table as the preferred approach to dealing with individual and household emissions.

In many cases, the lack of behavioural change may be due to structural factors, such that the range of alternative behaviours that an individual may reasonably undertake is physically or financially limited. However, there are many individuals for whom the alternatives are available and accessible, and who still fail to engage. The question is: why are these individuals failing to change their carbon-emitting behaviours?

The considerable literature on public perception of climate change (mostly Europe and U.S.-based) may provide some clues. A common finding across most survey studies is that, despite widespread concern about climate change, it is perceived as a distant threat - one that affects people in faraway countries, and/or future generations - with little personal relevance (Lorenzoni et al., 2007; Leiserowitz, 2006). Additionally, there appears to be widespread confusion about the causes, consequences and solutions to climate change, distrust in major sources of information, scepticism about the science 
behind climate change and a general reluctance to change lifestyle (Lorenzoni et al., 2007; Lorenzoni and Pidgeon, 2006). Add to this mix the large number of psychological barriers to behavioural change (Gifford, 2011) and the ever-present collective action problem, and one wonders why anyone would engage in behavioural change at all.

In this chapter, I propose that voluntary engagement by individuals and households in carbon-reducing behaviours might be significantly enhanced if climate change were to be framed clearly, and unequivocally, as a moral issue. This is because, typically, people do not want to be associated with behaviours they find morally wrong. In economic terms, one might say that, ceteris paribus, the greater the moral cost of a behaviour the less likely that behaviour (Levitt and List, 2007).

There is a wealth of empirical evidence indicating that moral concerns do indeed influence behaviour. Laboratory experiments repeatedly show that fairness concerns and inequity aversion operate under most conditions, such that players will cooperate even if this goes against self-interest (Fehr and Schmidt, 1999; Fehr et al., 2006). A review of the extensive literature on dictator games, for example, indicates that about $60 \%$ of the time, an average $20 \%$ endowment is made by the dictator (List, 2007). Furthermore, participants in economic experiments are more likely to cooperate if the game is framed in terms of "giving" rather than "taking" (List, 2007), or if they are playing "Community" rather than "Wall Street" (Ross and Ward, 1996), which suggests that individuals are highly responsive to cues indicating whether they should behave selfishly or cooperatively.

These findings are not just relegated to the laboratory. In real-world settings, people regularly engage in pro-social behaviours, such as donating to charity and buying ethical goods. Of course, one might argue that these behaviours are motivated by a desire for social approval rather than any inherent moral concern. Many lab-based studies confirm this to be the case: as player anonymity increases, cooperation and giving decrease (e.g. List et al., 2004; Hoffman et al., 1994). However, outside of the lab, people often engage in pro-social behaviours that are unobservable. For example, many people vote, consume green electricity and clean up after their dogs on quiet streets. It would be hard - if not implausible - to try to explain the wide range of voluntary behaviours solely in terms of social approval. 
This chapter argues that voluntary approaches to climate change reductions at the individual and household level will have a greater chance of succeeding if people perceive climate change to be a moral issue. This is not pretending in any way to be a novel idea. In the U.K, and more recently in the U.S., discourses about climate change have been framed in an increasingly moralistic way, such that certain behaviours are presented as good or responsible, and other behaviours as bad or irresponsible (Butler, 2010). However, these designations are rarely backed up with a clear moral argument that individuals can find meaningful.

That climate change is a moral issue is, I will argue below, indisputable. However, as we shall see, it has a number of features that make it difficult to apprehend as a typical moral problem. The purpose of this chapter is to identify these problematic features, to consider them in terms of moral philosophy, and to discuss how they might be re-cast within the structure of the archetypal moral problem, so that individuals may start to perceive climate change as a moral issue. This chapter also serves as a rudimentary review of the ethics literature relevant to climate change.

\section{THE MORAL DIMENSION OF CLIMATE CHANGE}

The climate change problem may be summarized thus: human activity affects the climate, and the ensuing climate change harms vulnerable others (the 'others' including poorer countries and future generations). Put in these terms, climate change is indisputably a moral issue. However, climate change has a number of features that make this particular moral problem very difficult to address.

In a standard moral problem, an agent imposes harm intentionally on another individual. Both individuals and the harm are usually identifiable, and the causal link between harming action and harm are also clearly identifiable. Take, for example, the case of Tom who intentionally kills Sue. Most would agree that his action is morally impermissible.

Now consider the following case: millions of people worldwide driving their cars, flying on holiday and heating their homes, add to carbon emissions in the atmosphere which lead to increasingly extreme storms, floods and droughts, as a result of which 
millions of other people will die. In this example, it is undeniable that some people are harming others. However, it is not clear how much one has contributed to what harm, and to whom. Additionally, there appears to be is no clear intention to do harm: the harms are imposed as a secondary effect of other behaviours - namely, the consumption of energy services.

These various characteristics of climate change make it difficult for individuals to perceive it as a moral problem, and this in turn hinders personal behavioural change based on moral concerns.

As noted by Jamieson (2010) and Greene (2003), our value system, which evolved in low-population, low-technology societies, is inadequate for dealing with moral problems of the type posed by climate change. Our "moral intuitions" are just evolutionary mechanisms that reflect the environment in which our social instincts evolved - an environment in which significant and meaningful social interactions took place face-to-face, and not across vast distances with complete strangers.

The present paper does not purport to suggest where and how our value system and sense of moral responsibility must evolve. Rather, keeping with the idea that climate change must be framed as a moral issue in order for individuals to engage in behavioural change, we will focus on the various features of climate change that distinguish it from standard moral problems, with a view to identifying how best to recast climate change within a conventional moral framework. To summarise, these are:

1. Nature of harm, and causal link between harming behaviours and harms, unclear.

2. Harms are (perceived as) removed in space and time with respect to harming behaviour.

3. Harms are produced as a secondary effect of other actions, and not intended.

4. Harms result from collective behaviour.

Notably, ethics has dealt with each of these 'problematic' features individually (although perhaps less so the collective action problem). Thus, there is a large literature 
in ethics on: the issue of ignorance with regards to morally-charged behaviours (discussed in Section 3); the moral permissibility of unintended secondary effects of one's actions (Section 4); and the influence of temporal and spatial distance on the perception of moral problems (Section 5). There is rather less literature on the ethics of collective action problems, with most of the focus being on the attribution of responsibility (discussed in Section 6). Although some of these complex issues are still under debate, there is at least a considerable intellectual foundation on which we can rely for the current analysis.

This chapter addresses two key questions. Firstly, do these various 'problematic' features outlined above reasonably justify behaviours that are responsible for harmful outcomes? For example, what is the moral permissibility of harmful actions when the acting agent is ignorant of the harm they are causing?

Secondly, and more importantly: how exactly do these 'problematic' features lessen - if at all - the perception of moral permissibility of the harming action? By understanding the mechanisms by which these features reduce or eliminate the perception of moral responsibility in morally impermissible situations, it may be possible to approach these features with scissors and glue, and reframe them so that the climate change problem might be perceived, clearly and unequivocally, by individuals as a moral problem.

\section{NATURE OF HARM UNCLEAR}

A defining characteristic of the public response to climate change is a lack of knowledge. In an extensive review of survey studies carried out in Europe, U.S. and Japan, Lorenzoni et al. (2007) found that survey respondents have a limited understanding of the causes of climate change, often identifying ozone depletion, deforestation and air pollution as the main causes. Interestingly, survey respondents rarely attribute climate change to their own personal behaviour, and mostly refer to generic causes such as "traffic" and "burning fossil fuels" (e.g. Bulkeley, 2000). Knowledge about the impacts of climate change is also vague and generic; Leiserowitz (2006) found that respondents mostly associate the term "climate change" with generic descriptors, such as "rising temperatures" and "world devastation". All in all, the 
empirical evidence suggests that public knowledge about climate change is vague and generic, and often confused.

What does this mean for the perception of climate change as a moral problem?

Standard moral problems involve actions that result in clearly defined harms, and in which the causal link between the acting agent and the victim is clear. But what if the acting agent is unaware of the harms that they cause?

Lack of knowledge or understanding can be used to absolve someone from moral responsibility. For example, it is used in criminal cases involving minors, who are treated with leniency because they are considered to lack understanding. The flip-side of this reasoning is that it incentivises ignorance with respect to actions in which harm may be caused. This very interesting issue - that of moral culpability under conditions of ignorance - has been discussed at length by Moody-Adams (1994), Zimmerman (1997), Rosen (2003) and Guerrero (2007), amongst others. I will not attempt to present the many complex arguments discussed in these papers, but will focus on the main points below.

\section{Ethics of moral ignorance}

The basic premise, proposed by Zimmerman (1997) and elaborated on by Rosen (2003), is that when a person acts wrongly out of ignorance, he is guilty only by virtue of being guilty for his ignorance. The key question to ask in such a case would be: should he have known? The implication is that when actions potentially have a moral consequence, we are obliged to ask questions, investigate, think, and take the necessary steps so as to act in the morally correct manner. Rosen refers to this as 'management of opinions'; if it is our opinions that lead us to act in one way or another, then we are responsible for managing them.

Guerrero (2007) builds on this idea by classifying ignorance about a wrong action into three types: 1) ignorance because the person has never thought about the issue, 2) ignorance because, even though the person has thought about the issue, she has come to false beliefs, 3) ignorance because, even though the person has thought about the issue, 
she doesn't know what to believe. He proposes that, in some circumstances, the first two types of ignorance may be excusable; the third type, he argues, is never excusable.

To illustrate, consider the example of Tom, who lives in the 1950s, has bought a car, and drives it around. He is completely ignorant of the fact that in fifty years time, climate change resulting from his actions will contribute to catastrophic consequences for future individuals. Given the lack of information on this topic, and the fact that the causal link between his action and the consequence is so complex and removed in time and space, there is very little reason to believe that he should have thought about the issue. We would therefore consider him blameless. He is, in effect, ignorant of the fact that he is ignorant of the impacts of his actions ${ }^{2}$.

Now consider Don, who buys his car in 2012. Assume that there is an extensive public transport service where he lives and works, and that Don is wealthy enough to buy a clean-fuel vehicle. However he drives his car everywhere, completely ignorant of the consequences of his actions. In the year 2012, there is ample information available in the public domain on the impacts of car driving on climate change and air pollution, and therefore, Don has a moral obligation to ask questions and become informed. In this sense, Don is guilty of his ignorance, and therefore his actions are morally wrong.

This type of ignorance ('affected ignorance') has been discussed at length by MoodyAdams (1994), who rebuts the view that people are blameless for wrong actions which are considered acceptable within their cultures. Thus, even though it is considered culturally acceptable for Don to drive his car as much as he wants, according to MoodyAdams he is not blameless because he has a moral obligation to question his actions (and as a result of his questioning, modify his actions appropriately), even if his culture condones such actions.

Now, consider that Don becomes thoroughly informed, and as result has developed incorrect notions about the effect of his driving on climate change. He may be blameless, unless he actively avoided engaging with both sides of the debate, and

\footnotetext{
${ }^{2}$ Of course, the fact that the car emitted smoke from the exhaust would surely alert 1950's Tom to the fact that his car might be polluting the air. Therefore, he might not be considered fully blameless, but for the purpose of this exposition, we will consider him mostly blameless.
} 
sabotaged his own attempts at discovery, in which case his ignorance would similarly be considered 'affected'.

Finally, consider that - despite reading up extensively on both sides of the debate - Don is unsure as to what is right and wrong. Guerrero (2007) argues that, in the absence of a belief, and given the potential of real harm, he should not drive his car. To do so would be morally wrong. This is, in effect, a moral precautionary principle.

Unfortunately, the precautionary principle is somewhat anathema to a competitive market-based society, which favours bullish, risk-taking behaviour over prudence and caution. As I will discuss below, ignorance in all its forms, is one of the main justifications used by individuals to continue engaging in carbon-emitting behaviours, and it is unlikely that a precautionary principle will change much.

\section{Public ignorance about climate change}

As noted earlier, empirical studies have found that, despite widespread awareness about climate change, there is confusion about the causes, consequences and solutions to climate change. Thus, the types of ignorance predominant with respect to climate change are 2) (ignorance from false beliefs) and 3) (ignorance from confusion) particularly the latter.

According to Guerrero, confusion does not justify actions with morally questionable outcomes. In the absence of a firm belief, we should abstain from acting just in case. According to this reasoning, individual carbon-emitters are guilty of wrong-doing: unable to understand whether their actions are wrong, they continue to drive and heat their homes, despite potentially harmful outcomes. As for individuals who are climate change sceptics, the question is more complex - have they really become informed, or is their ignorance motivated by private interests, such as a reluctance to change their lifestyles? If their belief is informed, then, say the ethicists, they are free from blame.

Despite Guerrero's claim that ignorance stemming from indecision about consequences does not justify wrongdoing, it does not carry the moral weight that an actual belief in negative consequences carries. For example, if I believe that killing animals is wrong, 
then I will find it harder to eat meat than if I am merely unsure of my opinion on this matter.

Unfortunately, one of the reasons that there is widespread confusion about climate change is very simply, that the information in the public domain is currently confusing and often contradictory. Media coverage of climate change has largely focused on scientific uncertainties and political disagreements (Carvalho and Burgess, 2005), in keeping with the notion that: "in news terms, conflict sells more than consensus" (Shanahan, 2007). As noted by Boykoff (2007), between 2003 and 2006, newspaper reporting of climate science in the U.S. and U.K. gave equal coverage to both sides of the climate change "debate", despite the fact that scientific consensus about the anthropogenic contributions to climate change had been reached in both countries around 2003/2004. This practise has only served to confuse the public, and undermine trust in science and evidence-based knowledge.

It seems evident that, if climate change is to be perceived as a moral issue, then the nature of the harm and its causes must be presented clearly and coherently, so that confusion is minimised. In particular, the link between particular individual behaviours and the impacts of these behaviours on vulnerable others, must be - if possible simplified and made clear. It might be argued that climate change is so complex that there is no way to simplify the causal link between actions and impacts. However, there are countless examples of complex cause-effect relationships that are presented to the public in simple terms. For example, we accept that drinking milk is good for our bones, although the process by which drinking milk benefits our bones is extremely complex and involves a large amount of biological and chemical detail. Similarly, we accept that passive smoking causes lung cancer. However, the process by which inhaled smoke from other people's cigarettes then turns into a cancer is largely ignored by the public.

It seems that the public information on climate change is bogged down with details about processes, and this renders the issue both confusing and impersonal to individual members of the public. What people want to know is: what are the specific impacts of my actions? Who or what gets harmed by my energy-related behaviour?

The question of impacts has only really been addressed over the last decade or so, prior to which, most analyses of climate change focused on one variable - the globally 
averaged surface temperature (Nordhaus, 1993). Although useful as an index of change, it is the impacts that result from these temperature changes - such as increased flooding, mortality rates, migration - that are meaningful to people.

Today, there is an increasing wealth of evidence on specific impacts of anthropogenic climate change, including human health effects (Patz et al, 2005; WHO, 2002), effects on the Arctic ice (IPCC, 2007; ACIA, 2004), effects on migration patterns (IPCC, 2007) and impacts on agricultural output (Reilly et al., 2003).

The formulation of clear, coherent message linking these impacts to energy-related behaviour would be the next obvious step - if indeed the public is to engage in the climate change issue. Optimally, such a message might say something along the lines of: every year, by driving into work, you produce (say) one tonne of carbon. One tonne of carbon has approximately $\mathrm{X}$ effect on crops/ arctic ice/ flooding severity/ other. This raises the question of whether individual energy-related behaviour can indeed be linked to a measurable impact. This is a matter for the climate scientists.

\section{HARMS PERCEIVED AS DISTANT}

A common perception amongst members of the public across the developed world is that climate change is not personally threatening (Lorenzoni et al., 2007; Lorenzoni and Pidgeon, 2006). Even in areas that are considered potentially vulnerable to the effects of climate change, members of the community show little concern about the problem (Bickerstaff et al., 2004). However, most respondents do consider climate change a serious threat - but only for future generations, or people living far away.

This is interesting, because the issue of harm to others tends to be a key driver of moral thinking, especially in Western society (Haidt and Graham, 2007). Part of the success of the anti-smoking campaign, for example, is attributed to a change in how the issue was framed. Where smoking had previously been portrayed as a personal choice with hazardous health consequences (but a personal choice nonetheless), the publication of the 1986 Surgeon's General Report, which documented the hazards 
of second-hand smoke ${ }^{3}$, made smoking a strictly moral issue (Rozin and Singh, 1999).

Why is it then, that, despite recognising that climate change poses a significant threat to vulnerable others, individuals fail to respond as they do to other situations involving harm to others?

\section{Ethics and 'distant' harms}

Consider the classic trolley problem devised by Philippa Foot in 1967 and expanded on by Judith Jarvis Thompson (1978): a trolley (i.e. train) is running out of control down a track. In its path are five people who have been tied to the track by a mad economist. In one scenario, you are given the option of flicking a switch, which will force the trolley down another track. Unfortunately, there is a single person tied to that track. What should you do? Flick the switch or do nothing? In another scenario, instead of a switch, you have the choice of pushing a fat man in front of the trolley; he will die, but his body will stop the trolley from killing the five. Again: what do you do?

Both alternatives involve killing one to save five, and yet, they elicit very different responses from people. Empirical evidence indicates that whereas people largely favour flicking the switch, they do not agree with pushing the man onto the tracks (e.g. Greene et al., 2001) ${ }^{4}$. This apparent inconsistency has been discussed and debated at length by philosophers, with a view to identifying a principle that would explain the different responses.

However, recent research in neuro-ethics suggests that the solution to the trolley conundrum lies not in our intuitive moral thinking or in any rational moral principle, but

\footnotetext{
${ }^{3}$ The issue of health-hazards of second-hand smoke had been first documented in a 1971 report by the U.S. Surgeon General, but the information was not made public until 15 years later in the 1986 report (Studlar, 2008).

${ }^{4}$ It is worth noting that philosophers had decided, a priori, that pushing the fat man was not acceptable whilst flicking the switch was indeed acceptable. There is a growing literature questioning the traditional 'intuitive' approach used by many moral philosophers to judge moral dilemmas. This approach starts with a moral intuition, and assuming that one's moral intuition is correct, sets out to construct and identify theories to defend it (Copp, 2010; Nichols and Mallon, 2005).
} 
in the way our brains are wired. In experiments carried out by Joshua Greene and colleagues, subjects' brain activity was scanned using functional magnetic resonance imaging (fMRI) whilst responding to questions about the trolley problem. Findings indicated that the fat man scenario generated greater activity in the affective/emotional parts of the brain, whilst the switch scenario activated parts of the brain associated with cognitive/controlled reasoning (Greene et al., 2001).

Pushing a fat man to his death with our bare hands sets off emotional alarm bells in our brains - and as result, we reject this action as highly immoral. However, flicking a switch is a hands-off affair, and so, the emotional alarm bells are not activated. The upshot of this is that we are more likely to reject harming actions that involve a strong personal component, compared to those which are more impersonal, even when the outcomes are identical. There have been a number of studies since, confirming the link between emotion and moral judgment (for a review, see Prinz, 2006).

Irrespective of the question of whether it is acceptable or desirable to base moral evaluations on emotional factors (for an impassioned argument against emotion-based moral judgment, in the context of climate change, see Grasso, 2011), the relevant issue in this chapter is: what does this mean for the perception of climate change as a moral problem?

\section{Public perception of climate change as 'distant'}

It is fairly evident that climate change, as framed at present, is unlikely to trigger emotional responses in people, which in turn means they are unlikely to evaluate climate change in strongly moral terms. Of course, the ideal would be that we, as individuals, could make reasoned, utilitarian moral assessments without the interference of our emotions, such that pushing the fat man onto the tracks would be considered morally akin to flicking the switch. It would also mean that we would consider, using Peter Singer's famous example, that saving a drowning baby in a pool (which action destroys your expensive shirt) equivalent to saving a dying child on the other side of the planet with a donation. Arguably, such a rational, utilitarian-minded world might be a better place. 
However, the simple fact is that utilitarian reasoning does not inspire strong moral convictions, and hence decisive actions based on these convictions. As noted by Rozin and Singh (1999), the most effective way of assigning a moral value to an action is through the recruitment of a strong, negative emotion, such as disgust. By associating a morally questionable action with a strong, negative emotion, it is much more likely that individuals will cease to engage in that behaviour. As Daniel Gilbert humorously puts it in a Los Angeles Times article: “[...] global warming is bad, but it doesn't make us feel nauseated or angry or disgraced, and thus we don't feel compelled to rail against it as we do against other momentous threats to our species, such as flag burning."5

Maybe climate change fails to make us feel nauseated or angry because we cannot see its victims, and we have no personal connection with them. It is noted by Walvin (2007) with reference to the abolition of slavery in Britain, that one of the key elements leading to abolition, was the appearance in the 1780s of large numbers of freed blacks who had fought on the British side against the North Americans, begging on the streets of London. Their presence, he argues, helped focus the debate on slavery.

More recently, the successful claim in 1992 by the James Bay Cree Indians against Hydro-Quebec, which was planning to damn the James Bay in Northern Quebec, was partly due to their 'up close and personal' approach, which took them to the streets and schools and legislature of New York (projected to be one of the main consumers of the electricity) to talk to people and explain their situation. On March $28^{\text {th }} 1992$, Mayor Cuomo cancelled the \$20-billion contract with the Quebec government (Heinzerling, 2007).

Of course, it may not be feasible (not to mention, rather carbon-intensive) to move large groups of climate change victims around the world to convince others to curb their carbon-emissions. However, maybe they could become more visible via the media.

The 'face of climate change' in the media has undoubtedly been that of the polar bear swimming to a sure death in a melting Arctic. The image has emotional content, so our sense of moral wrongness is stimulated - and yet there has been no evidence of major

\footnotetext{
${ }^{5}$ Gilbert, D. (2006) 'If only gay sex caused global warming,' The Los Angeles Times, 2 July. Many thanks to Grasso (2011) for this quote.
} 
reductions in individual carbon-emissions since the appearance of this image in our homes. Why? Some argue that ultimately, no-one cares that much about polar bears because they have no direct experience of them (Shanahan, 2007).

It might also be because, ultimately, it is not clear how we - as individuals - can act to save that particular drowning polar bear. The link between our energy-related behaviour and that polar bear is vague and uncertain (as discussed in Section 3), and the effectiveness of our actions as individuals depends on other individuals acting similarly (discussed in Section 6). It might also simply pander to the increasing public cynicism and distrust of climate scientists and journalists in general. Pulling the heartstrings of the public is perhaps no longer effective, and in fact, may be detrimental to the public willingness to engage in climate change.

It is suggested that the media might more effectively focus on the court room, where victims of climate change might next take their plight. Environmental lawyers and grassroots organisations have started to use litigation and other legal procedures as the means to effect change in this area (Martel, 2007; Aminzadeh, 2007). In the U.S. alone, 431 cases have been filed related to climate change litigation (Gerrard and Howe, 2012). So far, it appears that there have been no successful climate change claims made by victims, although Dahl (2007) claims it is just a matter of time.

However, there have recently been some victories in the court-room where prevention of climate change was used as the defence. For example, in September 2008, six Greenpeace climate change activists were cleared of causing $£ 30,000$ of criminal damage at a coal-fired power station in Kent, UK. Their defense rested on the argument that they were trying to prevent climate change from affecting property around the world (the power station, incidentally, produced 20,000 tonnes of $\mathrm{CO} 2$ daily) (Vidal, 2008).

Media attention to these climate change-related court cases can serve to raise the profile of the victims, and potentially increase the perception that we are effectively 'pushing them onto the train tracks'. Furthermore, successful claims could signal quite strongly the moral impermissibility of carbon-emitting behaviour (and might directly affect public pockets, if governments or companies have to pay compensation). 


\section{HARMS AS EXTERNALITIES}

Environmental issues, such as climate change, have been critical in drawing attention to the problem of third-party impacts, or 'externalities'. Negative spillover effects from economic activity are on the increase as populations grow and economies become increasingly interlinked. Furthermore, competitive pressures in a growing global market incentivise firms to externalise costs whenever and wherever possible. As Hahnel (2007) puts it: externalities are pervasive in everything we do.

The question is: is it morally permissible to harm others as a secondary effect of another activity, when the harm is not actually intended?

\section{Ethics and externalities}

Guidance within normative ethics on the acceptability of third-party impacts is provided by the much-disputed Doctrine of Double Effect (DDE), according to which, secondary effects of actions are acceptable only if not intended. Thus, for example, it may be permissible for Tom to kill Sue as a secondary effect of his behaviour, only if he did not intend it, and subject to the following constraints (Driver, 2007):

1. The act must be good in itself, or at least be indifferent.

2. The agent does not intend the third-party impact, and if they could avoid it, they would.

3. The agent is not seeking the third-party impact as an end, or means to an end.

4. The good end must be proportional to the third-party impact.

DDE is particularly used in medicine, and warfare, where certain actions have foreseeable negative consequences which are not intended. For example, DDE might be used to explore the moral permissibility of a national vaccination programme, in which it is foreseen that a small number of individuals might die due to negative reactions to the vaccine. DDE would condone the vaccination programme (assuming it saved many people) because the death of the few was strictly not intended. 
However, as pointed out by McIntyre (2001), there may not be a morally relevant distinction between intention and foresight. For example, if I foresee that my heavy smoking will affect the baby sleeping next to me, but I do not intend to harm the baby, am I free from blame? Most would agree not. The smoker can avoid harming the baby (stop smoking, move baby), and it is debatable whether the good end (nicotine rush) is proportional to the negative impact on the baby (coughing, increased chances of respiratory conditions).

Now, consider the example of someone driving their car to work each day, thus indirectly contributing to extreme climatic events in vulnerable areas. The act is good in itself - or at least indifferent (it gets the driver to work so she can provide for her family); she does not intend to harm anyone ${ }^{6}$. However, maybe she could avoid the harms by purchasing a cleaner vehicle, driving less, car-pooling or taking public transport? All of these options involve expenditures of time and/or money, and admittedly, some people simply do not have the resources to change their behaviour; in these situations, the behaviour might be considered morally acceptable. However, many people do have the resources to change their behaviour and fail to do so. The actions of these people are therefore morally impermissible.

Furthermore, it could be argued that the driver who chooses to keep her personal costs of driving down, by externalizing those costs onto the environment, is in effect using the environment as a means to an end. The atmosphere is absolutely essential for the driver's enjoyment of cheaper driving; she is using it to absorb the toxic gases from her car, which allows her to keep driving cheaply. And she knows (or indeed, she has a responsibility to know, as discussed in Section 3) that this is bad for others. She is, in effect, externalising costs onto others. She could argue that she did not intend to harm others; it was merely foreseen as a result of her using the atmosphere to absorb the toxic gases from her car. And thus, we come up against the 'distance' problem inherent in the

\footnotetext{
${ }^{6}$ She might even argue that she could not foresee harm either - but as discussed earlier, she would be guilty of such ignorance, and therefore culpable for actions based on this ignorance
} 
Trolley example: put a switch (or in this case, an atmosphere) between the acting agent and the victim, and morality seems to disappear from the picture ${ }^{7}$.

Finally, there is the proportionality constraint (number 4), which is essentially a utilitarian calculation, i.e. is the value of the externality proportional to the value of the intended outcome? Take as an example, our car driver, and another million car drivers. The value to them of using the air conditioning when they drive, say, is a function of comfort. Now, imagine that a small village in another country will be hit by extreme storms resulting from climate change, and that all of the villagers will die (and let us assume in this case, that it was the actions of those million and one car drivers using their air conditioning that contributed to this particular climatic event). Although results of a simple cost benefit analysis may well indicate that the proportionality constraint holds - i.e. the total value to the million car-drivers of using their air conditioning outweighs the total value to the 150 villagers of losing their lives - this leads to a situation somewhat akin to Derek Parfitt's 'repugnant conclusion' (Parfit,, 1984) i.e. the aggregate value of a tiny change in utility for a million people outweighs the aggregate value of a huge utility change for 150 people, such that we favour the million.

There has been much discussion in the literature on the validity and fairness of aggregation in welfare analysis (see Chapter 6 in Yeager (2001) for a summary of the debate), so I will not attempt to address this here. Suffice to say that DDE would probably allow the car driver to use her air conditioning in the above example, due to the proportionality constraint holding, despite what appears to be a morally questionable outcome.

\section{But I didn't intend it!}

DDE is problematic for the various reasons outlined above (i.e. intention and foresight overlapping, proportionality constraint favouring majorities with small utility gains),

\footnotetext{
${ }^{7}$ Of course, we could argue that there are two actions in this example that should be considered separately: 1) driving a car and 2) polluting the atmosphere. If we focus on the action of polluting the atmosphere, then the foreseen harm to the third party might be morally inadmissible (assuming the polluting action is avoidable).
} 
however, in the absence of any other normative theory on third-party impacts, DDE will remain the primary source of guidance on the morality of third-party impacts. Using DDE as a guide, harms posed to others as secondary effects of carbon-emitting behaviours such as car-driving, may be considered morally unacceptable - if only in reference to constraint 2 (if they could avoid it they should).

Thus, the moral permissibility of externalities resulting from energy-related behaviour hinges on the avoidance issue. Take for example, the success of smoking bans worldwide. The moral argument - that smoking harms others - was coupled with the fact that smokers did not have to smoke in public places, and this made for a very compelling argument. In the case of energy-related behaviour, the argument is less poignant: many people need their cars, appliances and central heating to secure basic standards of living. Should the moral message about climate change harming others successfully come across, it is not clear that individuals will be able to avoid engaging in the harmful behaviour, simply due to a lack of options.

\section{HARMS FROM COLLECTIVE BEHAVIOUR}

The collective action question is possibly the most complex issue to tackle with regards to individual reductions in carbon-emissions. Here we have multiple agents, often acting in ways that are not harmful in of themselves, all contributing to a greater harm. Any one of these actions individually will not cause harm, and it is only through the combination of all these actions that the harm occurs.

As we have seen, one of the features of archetypal moral problems is a clearly defined acting agent. In the example of Tom who kills Sue, the acting agent is clearly defined, and so the question of attribution of responsibility, or blame, is simple. The moment we have multiple agents acting individually, and contributing negligible amounts to a greater overall harm, we have an agency problem. Who exactly is responsible? And for what fraction of the harm? In order for there to be personal moral responsibility, there must be a clearly defined acting agent.

The question of where to locate responsibility for collective action problems is the subject of intense debate in moral philosophy, and will be reviewed below. In addition, I 
will briefly review the extensive literature on solutions to collective action problems, mostly generated in economics, social psychology and game theory. This literature may provide some indication as to how the mechanism of the collective action problem reduces the perception of individual moral responsibility, and consequently, may provide some guidance as to how to overcome this problem.

\section{Ethics and the collective action problem}

The climate change collective action problem is often portrayed as a Prisoners' Dilemma (PD), in which the individual is faced with two choices: to cooperate i.e. restrict one's emissions, or to defect i.e. not restrict one's emissions. To cooperate would require the individual to make personal short-term sacrifices for collectively long-term benefits, and this would only make rational sense if all (or a significant most) other individuals also cooperate.

From an ethical perspective, cooperation is generally considered the morally superior position: a Kantian approach would enjoin the participants to always cooperate, whatever the final outcome, the reasoning being that we must always do what we would want everyone else to do (the Categorical Imperative); a utilitarian perspective would conclude that it is better to cooperate because it leads to the greater good; a contractarian perspective (e.g. Gauthier, 1986) would consider cooperating not just the moral choice, but the self-interested choice - cooperating with the expectation that the other participant cooperates. In summary, there is a general consensus that, in collective action situations, cooperation is the morally right, or good, choice.

What is less clear is the question: where do we locate responsibility for initiating, and sustaining, cooperation and hence, positive collective action? Do we locate this responsibility in the collective itself, or in the individuals that make up the collective?

There is an ongoing debate amongst moral philosophers about this issue (although it is generally approached as an ex post question, after the fact of non-cooperation). Proponents of 'collective responsibility' argue that groups and collectives can be considered moral agents in their own right, who cause, and are blameworthy for, morally questionable actions (Smiley, 2010). However, it is generally agreed that not all 
collectivities are appropriate sites for moral responsibility, and only groups with wellordered decision-making procedures in place ('conglomerate collectivities') are considered appropriate. This is primarily because these types of groups contain an identifiable moral agent (i.e. the governing or representative body) that makes the decisions that inform the group actions (Smiley, 2011). Random groups of individuals ('aggregate collectivities') with no formal decision-making structure are generally considered inappropriate sites for moral responsibility.

Critics of the idea of collective responsibility highlight the fact that it is individuals who contribute to a collective action, and that there is no such thing as a 'collective mind' that can produce a collective intention. Only individuals, they argue, can have moral agency. Their main criticism, however, is directed at the non-distributional nature of collective responsibility. Specifically: should a whole collectivity be held responsible for the actions of particular group members?

This is a fascinating debate, but the relevant question for this chapter (should moral responsibility about climate change impacts be directed at individuals, or at collectives?) remains unanswered. Given that ethics does not help us resolve this question satisfactorily, we must look elsewhere for some guidance on how best to allocate responsibility.

\section{Solutions to the collective action problem}

There is a vast literature in economics and social psychology, mostly involving experimental methods or field research, which explores potential solutions to collective action situations. This literature has been reviewed extensively in Kollock (1998), so this will not be repeated here. The aim of this section is to briefly review the literature so as to identify how individual-level solutions fare in comparison to group-level solutions. This may give us some indication as to where to locate responsibility for the climate change problem.

Individual-level solutions to collective action problems - mostly identified in lab-based studies - typically aim at enhancing reciprocity between individuals. This can be done by: a) encouraging communication between individuals, b) ensuring interactions between individuals are frequent or durable, c) increasing identifiability of individuals 
and transparency of their actions, and d) by providing mechanisms by which individuals can punish non-cooperators. Generally, the more conditions are met, the greater the likelihood of cooperation ${ }^{8}$.

In a laboratory setting, the desire to cooperate can be assisted by facilitating the above conditions in the game. This may be a simple process when the game situation involves a handful of agents. The challenge in the climate change context is how to facilitate these conditions amongst the vast, dispersed and non-unified collection of individuals and institutions that contribute in uncertain ways to climate change. As the size of the collective increases, individuals find it harder to communicate with each other, to monitor each other's behaviour, and to sanction the behaviour of others, leading to a decline in cooperation. Furthermore, as group size increases, individuals tend to feel increasingly powerless to effect meaningful change.

This perceived lack of efficacy has been identified by researchers as one of the main reasons that individuals do not cooperate in collective action problems. Kollock (1998) reviews a number of studies that find that, if a collective action problem is structured in such a way that individuals perceive themselves as able to have a significant effect on the outcome, then the chances of cooperation increase (e.g. Bornstein et al., 1990). One way in which the collective action problem can be restructured is to introduce thresholds, by using a step-level production function for the public good. In such functions, actions by up to $k$ individuals make no difference to the outcomes, but actions by $k$ or more individuals shifts the benefits upwards. In this situation, each of $k$ individuals' contributions is crucial to reach the threshold at which provision of the public good becomes positive, and none can free-ride (or else the threshold is not reached). In these situations, individuals are much more likely to cooperate (Ostrom, 2002).

Additionally, the creation of a minimal number of individuals who can affect change $(k)$ confers an important sense of group identity upon those individuals, and this has been

\footnotetext{
${ }^{8}$ However, cooperation likelihood can be influenced by manipulating these conditions individually. For example, communication has been found to have a strong positive influence on cooperation, independent of other influences (see Balliett, 2010 for a meta-analysis of over fifty studies), whilst anonymity (i.e. lack of identifiability) has been found to decrease cooperation likelihood, ceteris paribus (see Levitt and List, 2007 for a review).
} 
shown to significantly increase the chances of cooperation within groups (Brewer and Kramer, 1986; Chen and Li, 2009). In fact, the impact of group identity is so strong that it increases cooperation even if the group is composed of strangers assigned to arbitrary groups, as in the seminal studies by Henri Tajfel and colleagues (1971; 1974). Furthermore, experimental studies by Rapoport et al. (1989) and Bornstein et al. (1990) have found that combining a step-level function and group identity, with groups competing against each other for a prize stimulates intragroup cooperation even further.

Returning to the question of moral responsibility: it is clear that individuals have personal moral responsibility in collective action problems such as climate change, but given the large number of individuals involved, and the perceived lack of efficacy associated with individual contributions to solutions, any sense of personal moral responsibility is likely to be highly diluted. It is suggested that a reframing of the problem in terms of attainable thresholds and associated group actions, might help to recast climate change as a moral issue in the traditional sense. How do-able this is in the context of climate change is another matter. Will it be possible to translate the energyuse of a collective such as a university for example, to a measurable impact - such as the loss of $X$ acres of land in low-lying islands? This, yet again, is a matter for the climate scientists.

\section{Public moral responsibility in the $\mathrm{CC}$ collective action problem}

Climate change, as it is currently presented to the public, suffers from a serious agency problem. There is no clear indication about who is responsible for what. As noted at the beginning of this section: for there to be personal moral responsibility, there must be a clearly defined acting agent. So how do we locate our acting agent?

Framing of the climate change collective action problem in terms of individual responsibilities is problematic for the very simple reason that individual contributions to climate change are almost negligible. Consequently, individuals are not likely to feel strongly about their moral responsibility in this context. Vandebergh (2005) suggests that appropriate presentation of information about individual impacts is crucial to make individuals assume moral responsibility for climate change impacts. Thus, he suggests 
that information on individual impacts (say, from driving) might be presented in terms of impacts over an extended period of time.

On the other hand, framing climate change in terms of collective responsibilities can be problematic too. One of the major arguments in ethics against the concept of collective responsibility is that it liberates individuals from personal responsibility. This is particularly important with regards to climate change, which involves a very large and dispersed collective made of individuals who have little influence on each other's behavior. Personal responsibility is likely to be highly diluted in this context.

However, individuals are also members of smaller collectives, such as: their workplace, local neighbourhood, sports centre, resident's association, parent's group, religious group and so on. Should one of these collectives - having come to the conclusion that climate change is a moral issue - decide to change their energy-related behavior, it is arguable whether the individual members would be liberated from personal moral responsibility. If the individual identifies with the collective, and if most other individuals within the collective feel similarly, then it is considered likely that the individual will take on the moral responsibility of the collective as their own.

The important work by Elinor Ostrom (1990) on communal tenure arrangements for the management of environmental ecosystems, such as fisheries, demonstrated that collective action problems could be overcome by small-scale communities without any need for external support or coercion. In these communities, the aforementioned conditions for cooperation (communication, transparency, repeated interactions and ability to punish defectors) were always present, and sanctioning costs were modest. Additionally, a sense of 'group identity' would have most likely been present.

Given the difficulty in convincing millions of individual energy-users to cooperate with complete strangers, it might be more effective to encourage cooperation within the aforementioned small-scale collectives (e.g. workplace, resident's association), such that they engage in carbon-reducing actions. Incentives for cooperation might come in the form of formal public recognition for efforts, such as certification schemes. Other incentives might include infrastructural assistance, subsidies or tax breaks. Furthermore, these approaches would serve to enhance the social capital of these small-scale 
collectives and of the wider society that they belong to, thus enhancing the ability of individuals within these collectives to deal with long-term collective action problems.

In short, by reframing the climate change problem in terms of attainable thresholds and associated group actions by small-scale collectives, we might help to overcome the agency problem inherent in this collective action problem. How do-able this is in the context of climate change is another matter. Will it be possible to translate the energyuse of a collective such as a university for example, to a measurable impact - such as the loss of $X$ acres of land in low-lying islands? This, yet again, is a matter for the climate scientists.

\section{RECASTING CLIMATE CHANGE WITHIN A STANDARD MORAL FRAMEWORK}

In ethics, climate change is viewed as a 'perfect moral storm' (Gardiner, 2006) because it presents so many challenges to conventional moral thought. Ideally, we would become aware of the pitfalls in our conventional moral appraisal processes, most of which are rooted in our evolutionary past, and upgrade our values and sense of responsibility to adjust to our new highly-populated and globalised world. However, this chapter argues that, in the meantime, whilst we adjust our moral thinking to the new world we live in, much of the moral confusion associated with climate change might be resolved by reframing the problem.

Specific recommendations, aimed at policy-makers, activist groups and the media, for how this might be achieved, include:

1) Make the nature of the harm clear.

This would require more effective communication efforts, involving a whittling away of the huge amount of detail (which, should the public want it, can be made readily available) and development a clear and coherent message focusing on final impacts. Climate science is producing an increasing wealth of evidence on impacts, and it is up 
to experts in the public communication of science to formulate this information in useable and coherent forms that are meaningful to people.

2) Reduce the perception of temporal and spatial distance of impacts, by increasing visibility of affected human communities and groups.

Consider the example of the James Bay Cree action against Hydro-Quebec, discussed in Section 4. Activist groups and other interested organisations could follow suit and assist affected groups so as to increase their visibility to the general public.

Another approach, such as that taken up by environmental law firms, is to embark on court cases - these are likely to raise the profile of the victims of climate change and raise public awareness. Furthermore, successful claims could signal the moral impermissibility of carbon-emitting behaviour (and might directly affect public pockets, if governments or companies have to fork out large sums of money). The perception of distance between acting agent and victim may therefore be shortened considerably.

3) Emphasise the moral impermissibility of avoidable behaviours and make clear which options are available.

The impacts of climate change on third parties are not intended; they are merely (foreseen) negative spillover effects from our use of energy to secure basic standards of living. The moral fibre of this issue hinges on the question: is the externality avoidable? If it is avoidable (if temporal, financial and other relevant constraints allow), then, morally, to continue such behaviour is impermissible.

This is an important argument as it places greater responsibility onto those who can avoid certain behaviours - and for the most part, this refers to higher-income individuals and families, who are more likely to own cars and large houses with high energy requirements. However, as noted, avoidability with regards to essential behaviours, such as travelling to work, implies the existence of alternatives, such as adequate public transport, car-pooling options, cycling lanes, clean-fuel refuelling stations and so on. As alternatives become readily available, it becomes easier to avoid harmful behaviours. 
4) Reframe the problem in terms of moral responsibilities of small-scale collectives and groups.

The problem should be reframed, not in terms of individuals adding to a global calamity through tiny actions, but in terms of empowered groups of individuals who can effect real and measurable change.

\section{Conclusion}

The aim of this chapter was to identify the various features of the climate change problem that distinguish it from standard moral problems, and to review the relevant ethics literature addressing each of these problematic factors so as to identify how best to re-cast climate change within a conventional moral framework. It is suggested that much of the moral confusion associated with climate change might be resolved by reframing the problem in terms of specific impacts on highly-visible groups of victims that can be avoided by groups of empowered individuals who can - and morally, should - effect real and measurable change.

There is of course a danger in resorting to moralisation in order to change people's behaviour. The very argument used in this chapter to justify the framing of climate change in moral terms - that it will make people change their ways - is also a dangerous argument, because it implies that question of good/right versus bad/wrong has a very powerful hold on people - and this can be used to ill effect. Throughout time, vested interests have used morality to justify prejudiced and oppressive policies. The liberation movements of the 60's and 70's partially liberated us from institutionalised forms of oppression - racism, homophobia, oppression of women - that had been couched for centuries in moral terms (see Hamilton, 2008 for an interesting discussion). Most people don't want to go back there.

However, this does not mean that we should throw away morality for good. The question of whether something is right or wrong is at least a level above the question of what is in one's self-interest. In a sense, the question is a tool for obtaining an 'ideal' using Bertrand Russell's definition of ideal as: "something having (at least ostensibly) 
no special reference to the ego of the man who feels the desire, and therefore capable, theoretically, of being desired by everybody" (p132, Russell, 1961). An ideal might be wishing there was no hunger in the world; or wishing there was no crime in your cities; or wishing that there was no war, and so forth. These are worthy desires, and should not be ignored off-hand.

It is considered that the role of morality in the context of climate change will be valuable for several reasons: it may help to reduce the impacts of climate change caused by individuals and families; it may serve to highlight the far-reaching harmful consequences of our energy-consumption behaviour; and hopefully, it will help to start shifting our dated moral value system towards one that is more suited to our overpopulated and globalised world.

\section{References}

ACIA (2004) Impacts of a Warming Arctic: Arctic Climate Impact Assessment, Cambridge University Press: Cambridge, UK

Aminzedah, S.C. (2007) 'A moral imperative: the human rights implications of climate change', Hastings International and Comparative Law Review, 30(2), 231-265

Balliet, (2010) 'Communication and cooperation in social dilemmas: a meta-analytic review', Journal of Conflict Resolution, 54(1), 39-57

Bickerstaff, K., Simmons, P. and Pidgeon, N. F. (2004) 'Public perceptions of risk, science and governance: Main findings of a qualitative study of five risk cases', Unpublished working paper, Centre for Environmental Risk, University of East Anglia, Norwich, UK.

Bornstein, G., Erev, I., and Rosen, O. (1990) 'Intergroup competition as a structural solution to social dilemmas,' Social Behavior, 5, 247-260.

Boykoff, M.T. (2007) 'Flogging a dead norm? Newspaper coverage of anthropogenic climate change in the United States and United Kingdom from 2003 to 2006', Area, 39(2), 1-12 
Brewer, M.B. and Kramer, R.M. (1986) 'Choice behaviour in social dilemmas: effects of social identity, group size, and decision framing,' Journal of Personality and Social Psychology, 50, 543-549

Bulkeley, H. (2000) 'Common knowledge? Public understanding of climate change in Newcastle, Australia', Public Understanding of Science 9, 313-333

Butler, C. (2010) 'Morality and climate change: is leaving your TV on a risky behavior?', Environmental Values, 19(2), 169-192

Carvalho, A. and Burgess, J. (2005) 'Cultural circuits of climate change in UK broadsheet newspapers, 1985-2003', Risk Analysis, 25(6), 1457-1469

Chen, Yan and Li, Sherry Chin (2009) 'Group identity and social preferences,' The American Economic Review, 99(1), 431-457

Copp, David. 2010. "Experiments, Intuitions, and Methodology in Moral and Political Theory.”UC Davis Working Paper.

Dahl, R. (2007) 'A changing climate of litigation', Environmental Health Perspectives, 115(4), 204-207

DECC (2011) 'UK Climate Change Sustainable Development Indicator: 2010 Greenhouse Gas Emissions, Provisional Figures And 2009 Greenhouse Gas Emissions, Final Figures By Fuel Type And End-User', Department of Energy and Climate Change, $31^{\text {st }}$ March 2011

DfT (2010) Transport Statistics Great Britain: 2010, Department for Transport

Driver, J. (2007) Ethics: the Fundamentals, Blackwell Publishing: Oxford, UK

Fehr, E., Naef, M. and Schmidt, K.M. (2006) 'Inequality aversion, efficiency, and maximin preferences in simple distribution experiments: comment', The American Economic Review, 96(5), 1912-1917

Fehr, E. and Schmidt, K. M. (1999) 'A Theory of Fairness, Competition, and Cooperation', Quarterly Journal of Economics, 114, pp. 817.868.

Foot, P. (1967) 'The problem of abortion and the Doctrine of Double Effect in Virtues and Vices, Oxford Review, 5, 5-15

Gardiner, S.M. (2006) 'A perfect moral storm: climate change, intergenerational ethics and the problem of moral corruption', Environmental Values, 15, 397-413

Gauthier, D. (1986) Morals by Agreement, Oxford University Press: Oxford, UK

Gerrard, M.B. and Howe, J.C. (2012) Climate Change Litigation in the U.S.: Chart of Litigation Cases. Arnold and Porter LLP. Available on www.climatecasechart.com 
Gifford, R. (2011) 'The dragons of inaction: psychological barriers that limit climate change mitigation and adaptation', American Psychologist, May-June 2011

Greene, J. (2003) 'From neural 'is' to moral 'ought': what are the implications of neuroscientific moral psychology?', Nature Reviews, 847-850

Greene, J., Sommerville, R., Nystrom, L., Darley, J., \& Cohen, J. (2001) 'An fMRI investigation of emotional engagement in moral judgment', Science, 293, 21052108

Grasso, M. (2011) 'The ethics of climate change: with a little help from moral cognitive neuroscience', CISEPS Research Paper No. 7/2011 Working Paper, University of Milan, Bicocca

Guerrero, A.A: (2007) 'Don't know, don't kill: moral ignorance, culpability and caution', Philosophical Studies, 136, 59-97

Haidt, J. and Graham, J. (2007) 'When morality opposes justice: Conservatives have moral intuitions that liberals may not recognize', Social Justice Research, 20, 98-116

Hahnel, R. (2007) 'The case against markets', Journal of Economic Issues, XLI(4), 1139-1159

Heinzerling, L. (2007) 'Why care about the polar bear? Economic analysis of natural resources law and policy,' Working Paper, Georgetown University Law Center, U.S. Accessed from: http://scholarship.law.georgetown.edu/fwps_papers/46

Hoffman, E., McCabe, K., Shachat, K. And Smith, V. (2004) 'Preferences, property rights, and anonymity in bargaining games', Games and Economic Behaviour, 7(3), 346-380

IPCC (2007) Climate Change 2007: Impacts, Adaptation and Vulnerability. Working Group II Contribution to the Intergovernmental Panel on Climate Change, Fourth Assessment Report. Summary for Policymakers.

Jamieson, D. (2010) 'Ethics, public policy and global warming', in Climate Ethics, Gardiner, S.M., Caney, S., Jamieson, D. and Shue, H. (editors), Oxford University Press: New York

Kollock, P. (1998) 'Social dilemmas: the anatomy of cooperation', Annual Review of Sociology, 24, 183-214

Leiserowitz, A. (2006) 'Climate change risk perception and policy preferences: the role of affect, imagery, and values', Climatic Change, 77, 45-72 
Levitt, S.D. and List, J.A. (2007) 'What do laboratory experiments measuring social preferences reveal about the real world?', Journal of Economic Perspectives, 21(2), 153-174

List, J.A. (2007) On the interpretation of giving in dictator games, Journal of Political Economy, 115(3), 482-493

List, J.A., Berrens, R., Bohara, A. and Kerkvliet, J. (2004) 'Examining the role of social isolation on stated preferences', American Economic Review, 94(3), 741-752

Lorenzoni, I., Nicholson-Cole, S. and Whitmarsh, L. (2007) 'Barriers perceived to engaging with climate change among the UK public and their policy implications', Global Environmental Change, 17, 445-459

Lorenzoni, I. and Pidgeon, N.F. (2006) 'Public views on climate change: European and USA perspectives', Climatic Change, 77:73-95

Martel, J.S. (2007) 'Climate change law and litigation in the aftermath of Massachusetts v. EPA', BNA Daily Environment Report, 7(214), 1-11

McIntyre, A (2001) 'Doing away with the double effect', Ethics, (2), 111(2), 219-255

Moody-Adams, M.M. (1994) 'Culture, responsibility, and affected ignorance', Ethics, 104(2), 291-309

Nichols, S. and Mallon, R. (2005) 'Moral Dilemmas and Moral Rules', Cognition, 100(3), 530-542

Nordhaus, W.D. (1993) 'Reflections on the economics of climate change', Journal of Economic Perspectives, 7(4), 11-25

Nyborg, K., Howarth, R.B. and Brekke, K.A. (2006) 'Green consumers and public policy: on socially contingent moral motivation', Resource and Energy Economics, 28, 351-366

Ostrom, E. (1990) Governing the Commons: The Evolution of Institutions for Collective Action, Cambridge University Press: Cambridge, U.K.

Ostrom, E. (2002) 'Property-rights regimes and common goods: a complex link', in Common Goods: Reinventing European and International Governance, A. Windhoff-Héritier (editor), Rowman and Littlefield Publishers, Inc.: Oxford, England

Parfit, D. (1984) Reasons and Persons, Oxford University Press: New York

Patz, J.A., Campbell-Lendrum, D., Holloway, T. and Foley, J.A. (2005) 'Impact of regional climate change on human health', Nature, 438(17), 310-317 
Prinz, J. (2006) 'The emotional basis of moral judgments', Philosophical Explorations, $9(1), 29-43$

Rapoport, A., Bornstein, G. And Erev, I.. (1989) 'Intergroup competition for public goods: effects of unequal resource and relative group size', Journal of Personality and Social Psychology, 56, 748-756

Reilly, J., Tubiello FN, McCarl B, Abler D, Darwin R, Fuglie K, Hollinger S, Izaurralde C, Jagtap S, Jones J, S. Jagtap, J. Jones, L. Mearns, D.Ojima, E. Paul, K. Paustian, S. Riha, N. Rosenberg and C. Rosenzweig (2003) 'U.S. agriculture and climate change: new results', Climatic Change, 57:43-69

Rosen, G. (2003) 'Culpability and ignorance', Proceedings of the Aristotelian Society, 103(1), 61-84.

Rozin, P. And Singh, L. (1999) 'The moralization of cigarette smoking in the United States', Journal of Consumer Psychology, 8(3), 321-337

Russel, B. (1961) History of Western Philosphy, Routledge: London

Shanahan, M. (2007) 'Talking about a revolution: climate change and the media. An IIED Briefing', Institute for Environment and Development, Dec 2007

Smiley, M. (2011) "Collective Responsibility", The Stanford Encyclopedia of Philosophy (Fall 2011 Edition), Edward N. Zalta (ed.), Available on http://plato.stanford.edu/archives/fall2011/entries/collective-responsibility/

Studlar, D.T. (2008) 'U.S. tobacco control: public health, political economy or morality policy?' Review of Policy Research, 25(5), 393-410

Tajfel, H., Billig, M., Bundy, R., \& Flament, C. (1971) 'Social categorization and intergroup behaviour', European Journal of Social Psychology, 1, 149-178.

Tajfel, H. (1974) 'Social identity and intergroup behaviour', Social Science Information, 13(2), 65-93

Thompson, J.J. (1978) 'The trolley problem', The Yale Law Journal, 95, 1395-1415

Vandebergh,M.P., Barkenbus, J and Gilligan, J. (2008) 'Individual carbon emissions: the low-hanging fruit', 55 UCLA Law Review 1701

Vandenbergh, M.P. (2005) Order without social norms: how personal norm activation can protect the environment, Northwestern University Law Review, 99(3), 11011166

Walvin, J. (2007) Slavery - the emancipation movement in Britain, Lecture delivered on $5^{\text {th }}$ March 2007 at Gresham College, London. Available on 
http://www.gresham.ac.uk/lectures-and-events/slavery-the-emancipationmovement-in-britain

Whitmarsh, L. (2009) 'Behavioural responses to climate change: asymmetry of intentions and impacts', Journal of Environmental Psychology, 29, 13-23

WHO (2002) The World Health Report 2002, The World Health Organisation, Geneva

Yeager, L.B. (2001) Ethics as Social Science: The Moral Philosophy of Social Cooperation, Edward Elgar Publishing

Zimmerman, M.J. (1997) 'Moral responsibility and ignorance', Ethics, 107(3), 410-426 